\title{
High Precision Earth-Temperature Detection System Based on Platinum Resistance
}

\author{
Li Yan \\ College of Information Science \& Technology \\ Hebei Agricultural University \\ HeBei Baoding, China \\ 707412641@qq.com
}

\author{
Wang Fu-shun \\ College of Information Science \& Technology \\ Hebei Agricultural University \\ HeBei Baoding, China \\ wangfushun@yahoo.cn
}

\begin{abstract}
According to the measurement precision requirements during geothermal testing process, optimize the circuit design and segmented curve fitting were used, discussed the feasibility of realize high precision temperature detection. Platinum resistance were used as temperature sensing element, matched with high precision constant current source bridge in order to improve the precision of the hardware and the quadratic polynomial fitting and cubic polynomial fitting were analyzed and compared. Final experimental results show that the system made up the deviation intermediate detection process and achieved the purpose of high precision testing.
\end{abstract}

Keywords-Earth temperature; High Precision; Platinum resistance; segmented curve fitting

\section{INTRODUCTION}

In the hydrological geological science, agricultural environmental science and other fields, earth temperature is very meaningful data. Layers of thermal parameters include the formation of thermal conductivity and specific heat capacity and thermal diffusion rate,water parameters formation including moisture content, seepage velocity and so on, and these parameters acquisition, are directly or indirectly with soil temperature of the precision measurement ${ }^{[1]}$. Study soil temperature measuring, Help to study plant growth habit, ensure the quality of crops, and improve the agricultural production. On the environment geology, hydrogeology, soil science, and many other areas have very important significance ${ }^{[2]}$.

Based on platinum resistance as temperature medium, combined with high precision temperature measurement circuit, the low power consumption modulus conversion unit, through the single chip microcomputer control, segmented curve fitting the temperature sampling value, get the corresponding D-t curve, and compensate the nonlinear relationship of platinum resistance in the practical work, to achieve the purpose of accurate measurement of the temperature.

\section{SYSTEM'S DETECTION STRUCTURE}

Commonly used method of soil temperature measurement is using special thermal resistance or other temperature sensor for temperature measurement. It's measurement accuracy in the $0.1^{\circ} \mathrm{C}$, At present, this kind of method was most used to soil parameter measuring equipment in domestic and foreign ${ }^{[3]}$.

The detection scheme of this system was shown in figure 1. Temperature sensing element use EL - $700(100 \Omega)$ platinum resistance, the thermal resistance using thick film structure, in low temperature range has good stability and accuracy of measurement, in $259.34 \sim 630.74{ }^{\circ} \mathrm{C}$ range was identified as standard measuring devices by international scale IPTS - 68.Platinum thermal resistance of input/output characteristic in $0 \sim 850{ }^{\circ} \mathrm{C}$ range expressed as:

$$
\begin{aligned}
& R_{t}=R_{0}\left(1+A t+B t^{2}\right) \\
& \text { In range of }-200 \sim 0^{\circ} \mathrm{C} \text { expressed as: } \\
& R_{t}=R_{0}\left(1+A t+B t^{2}-100 C t^{3}+C t^{4}\right)
\end{aligned}
$$

The $\mathrm{R}_{0}$ for sensor calibration value $100 \Omega$, temperature coefficients was:

$$
A=3.97 \times 10^{-3} /{ }^{\circ} \mathrm{C}, B=-5.85 \times 10^{-7} /{ }^{\circ} \mathrm{C}^{2}, C=-4.22 \times 10^{-12} /{ }^{\circ} \mathrm{C}^{4} \text {. }
$$

Platinum resistance feels soil temperature variables, convert to resistance signal $\triangle \mathrm{R}$ and output to the measurement circuit. The constant current source driver bridge converted the $\triangle R$ sigle to voltage signal $\triangle U$, after amplification and low pass filtering (filtering out-of-band noise) unit, at last, got the analog signal which proportional relation to temperature variable.

In the design process, the temperature-sensing element, temperature measurement circuit, data conversion unit as a whole to be consider. Based on the overall accurate function and described digital quantity expression of $\mathrm{D}$, through piece wised fitting and inversion to series of discrete data $\mathrm{D}$, to obtain the function close to formula (1) and (2). Fitting error was controlled by the least square method. This kind of fitting method made D and $\mathrm{T}$ as parameters, compensated the signal deviation generated each of the intermediate links from platinum resistance to $\mathrm{A} / \mathrm{D}$ conversion process, and made more accurate in temperature measuring ${ }^{[4]}$.

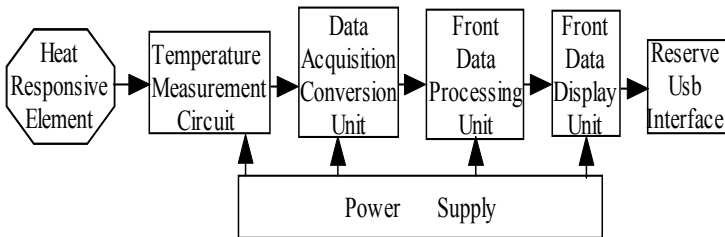

Figure 1. Temperature measurement system solutions

\section{PRECISION ANALYSIS OF HARDWARE DETECTION CIRCUIT}

Figure 2 showed the hardware structure of detection circuit. Platinum resistance uses the three-wire system access measuring bridge. 


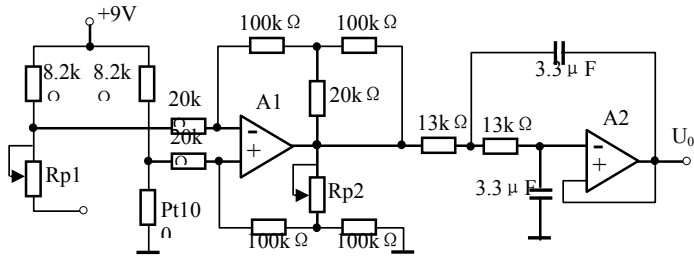

Figure 2. .Hardware structure of detection circuit

It can eliminate the influence of lead resistance on the accuracy of measurement, the operational amplifier A1 to signal amplification(Amplifier gain $\mathrm{K}$ can be controlled ), A2 and capacitance constitute a high order low-pass active filter, Filter out the useless clutter(Cut-off characteristic steep, Cut-off frequency set to $40 \mathrm{~Hz}$, to eliminate the interference of circuit power frequency effectively). Before the temperature measurement circuit working, Make the relative bridge arm resistance equal to the product, Make bridge in a state of balance, Output voltage $\triangle U$ was zero, When platinum resistance began to temperature, the change of the resistance capacity for $\triangle R$, the amplifier gain of $A_{1}$ for $\mathrm{K}$, the amplifier output voltage $\triangle \mathrm{U}^{\prime}$ as flow:

$$
\Delta U^{\prime}=K \Delta U=K \frac{\left(R_{0}+\Delta R\right) R_{3}-R_{1} R_{2}}{\left(R_{0}+\Delta R\right)+R_{1}+R_{2}+R_{3}} I
$$

The output voltage $\triangle U^{\prime}$ was sent into data acquisition conversion unit for $\mathrm{n}$ bit modulus conversion, assuming the switching voltage reference $V_{\text {REF }}$ for $5 \mathrm{v}$, Then the voltage accuracy of converter $\triangle V_{\text {REF }}$ can be expressed as $V_{R E F} / 2 n$, The converter output digital quantity as flow :

$$
\begin{aligned}
& D=\frac{\Delta U^{\prime}}{V_{R E F} / 2^{n}}=\frac{K \Delta U}{\Delta V_{R E F}} \approx \frac{K I \Delta R}{4 \Delta V_{R E F}} \\
& \left(\Delta R<<R_{0}, R_{1}, R_{2}, R_{3}\right)
\end{aligned}
$$

Form the equation can see that through the lower voltage reference, improving conversion digits or increasing

\begin{tabular}{|c|c|c|c|c|}
\hline \multirow{2}{*}{$\begin{array}{c}\text { Actual } \\
\text { Temperature }\left({ }^{\circ} \mathrm{C}\right)\end{array}$} & 16 Times Sample Value of One Temperature Point & \multirow[t]{2}{*}{ Final Result D } & \multirow{2}{*}{$\begin{array}{c}\text { Temperature } \\
\text { Estimated Value }\left({ }^{\circ} \mathrm{C}\right)\end{array}$} & \multirow{2}{*}{$\begin{array}{l}\text { Measurement } \\
\text { error }\left({ }^{\circ} \mathrm{C}\right)\end{array}$} \\
\hline & D1 ...... D16 & & & \\
\hline 10 & $\begin{array}{llllll}12847128551284312876 & 12865 & 12843 & 12854 & 12872\end{array}$ & 12855.25 & 9.9871 & -0.0059 \\
\hline 10.5 & $\begin{array}{llllll}\begin{array}{l}13494134821350213508 \\
13407\end{array} & 13490 & 13501 & 13510 & 13486 \\
\end{array}$ & 13493.89 & 10.5024 & +0.0024 \\
\hline 11 & $\begin{array}{lllllllll}14140 & 14149 & 14126 & 14128 & & 14131 & 14121 & 14113 & 14114 \\
14130 & & & & & & & & \end{array}$ & 14133.56 & 10.9861 & -0.0139 \\
\hline 11.5 & $\begin{array}{llllll}\begin{array}{l}14786147901476714762 \\
14780\end{array} & 14771 & 14788 & 14781 & 14759 \\
\end{array}$ & 14773.08 & 11.4856 & -0.0144 \\
\hline 12 & $\begin{array}{llllll}\begin{array}{l}15442 \\
15425\end{array} & 15391537815380 & 15430 & 15412 & 15397 & 15424 \\
\end{array}$ & 15416.61 & 12.0183 & +0.0183 \\
\hline$\ldots$ & $\cdots$ & $\ldots$ & $\cdots$ & ... \\
\hline 18.5 & $\begin{array}{lllllll}\begin{array}{l}23768 \\
23771\end{array} & 23712376223735 & 23754 & 23739 & 23733 & 23733 \\
\end{array}$ & 23742.13 & 18.4936 & -0.0064 \\
\hline 19 & $\begin{array}{llllll}24378 & 243462438724393 & 24377 & 24355 & 24379 & 24381 \\
24275\end{array}$ & 24381.11 & 19.0142 & +0.0142 \\
\hline 19.5 & $\begin{array}{llllll}\begin{array}{l}25038 \\
25025\end{array} & 250092504225051 & 25003 & 24987 & 25034 & 25012 \\
\end{array}$ & 25024.72 & 19.5095 & +0.0095 \\
\hline 20 & $\begin{array}{llllll}\begin{array}{l}25665256412566825677 \\
25640\end{array} & 25641 & 25663 & 25650 & 25655 \\
\end{array}$ & 25662.67 & 19.9941 & -0.0059 \\
\hline
\end{tabular}
the amplifier gain $\mathrm{K}$ and bridge circuit current I can make

TABLE I Part of the sampling results of $10^{\circ} \mathrm{C} \sim 20^{\circ} \mathrm{C}$ temperature rang

\section{CURVE FITTING PROCESS ANALYSIS OF D TO $t$}

During the temperature range of $-20^{\circ} \mathrm{C}$ to $60^{\circ} \mathrm{C}$, every $10^{\circ} \mathrm{C}$ was devided as a piecewise fitting in order to ensure fitting precision. A fitting function expression for:
A/D converter to improve sensitivity. Assuming the system $A / D$ conversion digits as $n=16$, the amplifier gain $K=200$, the bridge circuit current $\mathrm{I}=5 \times 10$ - $3 \mathrm{~A}$, then:

$$
D=2^{n} \times \frac{K I \Delta R}{4 V_{R E F}}=2^{16} \times \frac{200 \times 5 \times 10^{-3}}{4 \times 5} \Delta R=2^{16} \times 50 \times 10^{-3} \Delta R
$$

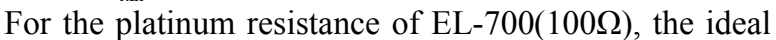
mathematical model of the $\mathrm{I} / \mathrm{O}$ relationship is as follows:

$$
R_{t}=a_{0}+a_{1} t+a_{2} t^{2}+a_{3} t^{3} \ldots+a_{n} t^{n}
$$

In the case of not affecting the measurement precision, using formula (1), (2) to approximate alternative, and substitution formula (5), can get:

$$
\begin{aligned}
D= & 327680\left(A t+B t^{2}\right) \quad\left(0 \leq t \leq 850{ }^{\circ} C\right) \\
D= & 327680\left(A t+B t^{2}-100 C t^{3}+C t^{4}\right) \\
& \left(-200{ }^{\circ} C \leq t \leq 0\right)
\end{aligned}
$$

\section{ORIGINAL DATA COLLECTION}

For each specific temperature $t$ should have a unique D to corresponding, with the $\mathrm{D}$ value, then looking for the relationship between temperature and the temperature point and the voltage signal which is converted by the $\mathrm{A} / \mathrm{D}^{[5]}$. by using of least squares method piecewise fitting D - $t$ curve, combined with the collected digital quantity $\mathrm{D}$ can get practical temperature.

Using constant temperature tank to simulate $0^{\circ} \mathrm{C} \sim$ $60^{\circ} \mathrm{C}$ temperature field when testing, every $0.1{ }^{\circ} \mathrm{C}$ as a temperature sampling point, for each sampling point sample 16 times. Eliminated the maximum and the minimum sample in the group of 16 simples, and the remaining 14 value take average as the sampling results, so that we can effectively remove bulky error and random error influence. Part of the sampling results of $10^{\circ} \mathrm{C} \sim 20^{\circ} \mathrm{C}$ range were intercepted and shown as table 1 , the interval for $0.5^{\circ} \mathrm{C}$. 
the curve constraint, thus reduce the interval experimental data deviation of fitting curve. Third, suitable interval of fitting curve. Generally, in the experimental data interval has small deviation, while outside interval, deviation will far from the prediction and higher order fitting lead to the greater error ${ }^{[6]}$.

Comprehensive consideration the above factors, decided to use quadratic polynomial and cubic polynomial to go fitting processing separately, and compare the measurement accuracy they can reach. In temperature range of $10{ }^{\circ} \mathrm{C} \sim$ $20^{\circ} \mathrm{C}$, under the quadratic polynomial fitting, the measurement error was shown in figure 3 ,it clear that the error in $-0.04^{\circ} \mathrm{C}$ to $0.04^{\circ} \mathrm{C}$ range; However, under Cubic polynomial fitting, the measurement error showed in figure 4, the error range form $-0.02{ }^{\circ} \mathrm{C}$ to $0.02^{\circ} \mathrm{C}$, measuring precision had be increased remarkably. Therefore, the system decided to select cubic polynomial fitting.

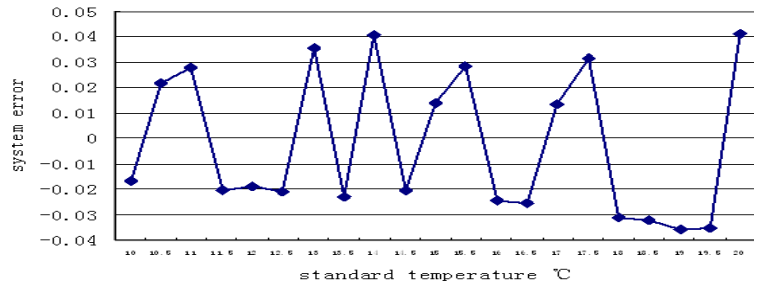

Figure 3. Error distribution curve under quadratic polynomial fitting

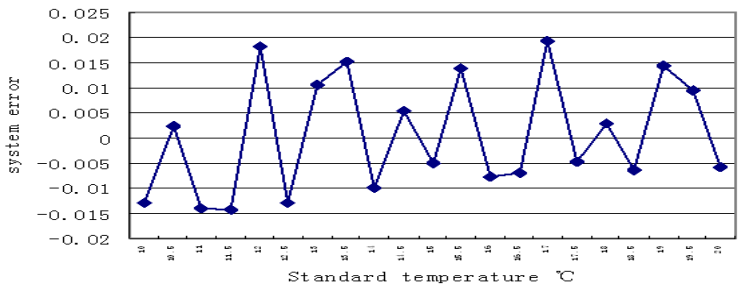

Figure 4. Error distribution curve under cubic polynomial fitting

In the formula (8), $\mathrm{m}$ value for 3 , the $\mathrm{D}$ and $\mathrm{t}$ value of $10^{\circ} \mathrm{C} \sim 20^{\circ} \mathrm{C}$ temperature range substituted in it and got:

$$
\left[\begin{array}{cccc}
1 & D_{1} & D^{2} & D^{3} \\
1 & D_{2} & D_{2}^{2} & D_{2}^{3} \\
1 & D_{n} & D_{n}^{2} & D_{n}^{3}
\end{array}\right] \quad\left[\begin{array}{llll}
a_{0} & a_{1} & a_{2} & a_{3}
\end{array}\right]^{T}=\left[\begin{array}{llll}
T_{1} & T_{2} & \cdots & T_{n}
\end{array}\right]^{T}
$$

Namely the type: $A \alpha=T$

Above equation, the sampling number $\mathrm{n}$ is greater than the number of unknown quantity, so it is an inconsistent equation. Used the least square method to solve it in order to ensure fitting accuracy, The total mean square error $\delta$ was $\|T-A \alpha\|_{2}^{2}$.Make it the minimum, and the could get the $\alpha$ value, so must solve the following equation:

$$
\frac{\partial \delta}{\partial \alpha}=-2 A^{T} T+2 A^{T}-A \alpha=0
$$

Above, the A and T was known, solute the vector $\alpha$, namely determined the fitting polynomial coefficient.

Fitting process can use the polynomial fitting function provided in MATLAB software $\mathrm{P}=$ polyfit $(x d a t a, y d a t a, n)$.

Above, $\mathrm{n}$ said the highest order number of polynomial; xdata, ydata said the data will be fit, they were input with the way of array; the output $\mathrm{P}$ was a row vector of a polynomial coefficient.

From table 1 it's clear that sampling results D value was complex relatively, in order to simplify fitting process, normalizing method was used before fitting. Such as formula (11) shown.

$$
D^{\prime}=\left(D-D_{\text {min }}\right) /\left(D_{\text {max }}-D_{\text {min }}\right)
$$

After derivation, Got the fitting function of $10^{\circ} \mathrm{C} \sim 20^{\circ} \mathrm{C}$ temperature range as flow:

$$
T(D)=a_{3} D^{3}+a_{2} D^{2}+a_{1} D+a_{0}
$$

Above, $\quad \mathrm{a} 0=\quad-\quad 0.0651, \mathrm{a} 1=0.000776, \mathrm{a} 2=\quad-$ $1.0174 \mathrm{e}-10, \mathrm{a} 3=1.9623 \mathrm{e}-15$.According to the fitting-function the D-t fitting curve shown as figure 5.

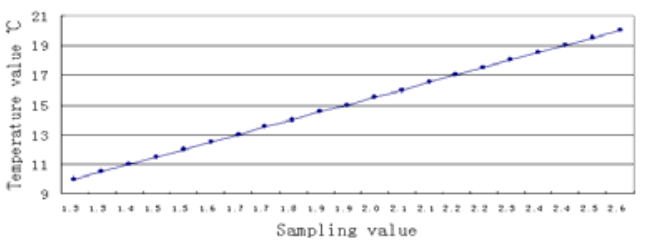

Figure 5. D-t fitting curve of $10^{\circ} \mathrm{C} \sim 20^{\circ} \mathrm{C}$ temperature range

\section{EXPERIMENTAL CONCLUSION}

In the high precision temperature detection system, through improving measurement circuit structure and using least squares D-t segmented curve fitting, improved the accuracy of detection effectively. The detection error was controled in the range of $-0.02^{\circ} \mathrm{C}$ to $0.02^{\circ} \mathrm{C}$, reached the accurate detection requirements. In the actual use process, the heat element can design into differential structure, reduce the influence of nonlinear error further more, and improve the detection sensitivity.

The following projects funded the paper: Agricultural University of Hebei fund support project (Fs20100506); Agricultural University of Hebei fund support project (Fs20100505); Scientific research and development plan of Baoding support project (12ZN020).

\section{REFERENCES}

[1] Wu Qi-zhong, etc. Experiment of Soil Thermal Diffusivity in Cities [J]. Journal of Atmospheric and Environmental Optics, 2007, 2(4): 257-262

[2] Yu Ming-zhi, Fang Zhao-hong. A Method for the On-site Testing of Average Thermo-physical Parameters of Underground Rock Soil [J]. Journal of Engineering for Thermal Energy and Power, 2002(17): 489-492

[3] Xue Qing-hua. The Study of Temperature Measuring Technology of Multichannel and High Accuracy [D]. Wuhan: Huazhong University of Science and Technology press, 2007.

[4] Yi Xian-jun, Wen Xiao-ling, Liu Cui-mei. Study of high-precision temperature measurement based on platinum resistance $[\mathrm{J}]$. Transducer and Microsystem Technologies, 2009, 28(1): 49-51

[5] Yang Yong-zhu. Linear Compensation for Platinum Resistance Thermometers with High Accuracy and Its Realization in Intelligent Instruments [J]. Instrument Technique and Sensor, 2000(8): 44-46

[6] Shang Yu-pei, Shi Lin-suo, Zhang Zhen-ren. Application of least square method in temperature measurement with high accuracy [J]. Transducer and Microsystem Technologies, 2000, 19(1): 47-48 